\title{
Matrix Isolation and Computational Study of the Photochemistry of 1,3,2,4-Benzodithiadiazine
}

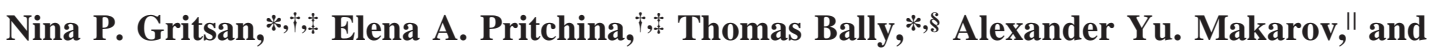 \\ Andrey V. Zibarev \\ Institute of Chemical Kinetics and Combustion, Siberian Branch of Russian Academy of Sciences, 630090 \\ Novosibirsk, Russia, Novosibirsk State University, 630090 Novosibirsk, Russia, Department of Chemistry, \\ University of Fribourg, Ch. du Musée 9, CH-1700 Fribourg, Switzerland, and Institute of Organic Chemistry, \\ Siberian Branch of the Russian Academy of Sciences, 630090 Novosibirsk, Russia
}

\begin{abstract}
Photolysis of 1,3,2,4-benzodithiadiazine (1) at ambient temperature yields stable 1,2,3-benzodithiazolyl radicals. In order to reveal the mechanism of this unusual transformation, the photochemistry of $\mathbf{1}$ was studied in argon matrices using IR and UV-vis spectroscopy. A series of intermediates, including four- and fivemembered heterocyclic and $o$-quinoid acyclic species, were characterized spectroscopically with the help of quantum chemical calculations. With selective irradiation, these intermediates can be mutually interconverted as well as converted back to the starting compound $\mathbf{1}$.
\end{abstract}

\section{Introduction}

An extensive family of polysulfur-nitrogen heterocycles, including both closed- and open-shell structures having an unusually high ratio of heteroatoms (nitrogen and sulfur) to carbon atoms has recently been discovered at the borderline between organic and inorganic chemistry. ${ }^{1-4}$ In particular, the persistent thiazyl (SN) $\pi$ radicals have emerged as attractive building blocks for molecular magnets and/or molecular conductors. $^{2-4}$ For example, one of the recently synthesized SN $\pi$ radicals reveals properties of a spin-canted weak ferromagnetic material below $36 \mathrm{~K}$ at ambient pressure and below $65 \mathrm{~K}$ at high pressure. ${ }^{3 \mathrm{a}}$ The carrier of the unpaired electron in these radicals is a 2 -center-3- $\pi$-electron fragment $(\mathrm{SN})^{\bullet}$, i.e., a sulfur analogue of nitric oxide $\mathrm{NO}^{*}$. It is the same moiety that constitutes the well-known molecular metal and low-temperature superconductor polythiazyl $(\mathrm{SN})_{x}{ }^{5}$

The structural versatility of compounds containing the SN fragment and the usually high chemical and thermal stability of thiazyl heterocycles ${ }^{2,6}$ provide opportunities for further investigations of new radicals and materials. For example, benzo-fused $\mathrm{SN} \pi$ radicals such as 1,2,3-benzodithiazolyls (Herz radicals) represent a less studied but potentially very promising class of such compounds.

Typically, Herz radicals are produced by reduction of Herz salts (1,2,3-benzodithiazolium chlorides). ${ }^{7}$ Recently we discovered a new approach to these radicals, ${ }^{8}$ i.e., the thermolysis or photolysis of 1,3,2,4-benzodithiadiazine (1), which gives rise to the stable Herz radical, 2, in quantitative yields (Chart 1). This method has also been successfully applied to prepare a number of new derivatives of radical 2 , including ones that are inaccessible by other pathways. ${ }^{8}$

* To whom correspondence should be addressed. E-mail: gritsan@ kinetics.nsc.ru (N.P.G.); Thomas.Bally@unifr.ch (T.B.).

Institute of Chemical Kinetics and Combustion.

$\doteqdot$ Novosibirsk State University.

$\S$ University of Fribourg.

"Institute of Organic Chemistry.

\section{CHART 1}<smiles>C1=NSc2ccccc2N1</smiles>
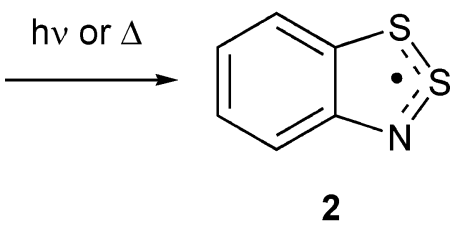

CHART 2<smiles>N#S1=Nc2ccccc2S1</smiles>

The possibility of generating stable SN radicals photochemically is especially promising in view of new applications of these heterocycles. However, nothing is known about the mechanisms of the thermal and photochemical reactions of 1,3,2,4-benzodithiadiazine (1), and apart from a few reports on the preparative photolysis of some sulfur-nitrogen heterocycles designed to isolate only final stable products, ${ }^{9}$ the photochemistry of poly-SN-heterocycles remains largely unexplored.

In our preliminary study, ${ }^{10}$ we showed that photolysis of $\mathbf{1}$ in a low-temperature glassy matrix results in the formation of intermediates which show strong absorptions peaking near 460 $\mathrm{nm}$. As these intermediates are electron paramagnetic resonance (EPR) silent, they must be diamagnetic. Heating of the samples to room temperature results in the disappearance of new absorption band and the formation of an EPR signal typical of the final radical 2. ${ }^{10}$ On the basis of the infrared (IR) spectral changes that were observed upon photolysis of $\mathbf{1}$ in a cryogenic argon matrix, thiazyl $\mathbf{3}$, was proposed as one of the intermediates (Chart 2). ${ }^{10}$

However, our subsequent studies revealed that the photochemistry of $\mathbf{1}$ in argon matrices is very complicated and that several intermediates must be involved in the process. This work is devoted to elucidating the mechanism by which $\mathbf{1}$ decays on 
photolysis using matrix isolation spectroscopy and quantum chemical calculations

\section{Experimental and Computational Details}

Compound 1 was synthesized following the published procedure. $^{1 \mathrm{a}}$

Spectroscopy in Argon Matrices. ${ }^{11}$ A few ground crystals of $\mathbf{1}$ were placed in a U-tube attached to the inlet system of the cryostat. A mixture of argon with $10 \%$ nitrogen (which is added to improve the optical quality of matrices) was flowed through the U-tube and slowly deposited on a CsI window (UV transparent quality, Korth Kristalle $\mathrm{GmbH}$ ) maintained at ca. $20 \mathrm{~K}$. During deposition the temperature of the U-tube was kept at a fixed value and varied for different samples between -12 and $22{ }^{\circ} \mathrm{C}$.

Photolysis of 1 was effected with a medium-pressure $\mathrm{Hg} / \mathrm{Xe}$ lamp with appropriate interference and glass filters. Electronic absorption spectra were obtained on a Perkin-Elmer Lambda 900 spectrometer $(200-1000 \mathrm{~nm})$. IR spectra were measured on a Bomem DA3 interferometer $\left(4000-500 \mathrm{~cm}^{-1}\right)$ with an MCT detector. The percentage of photoconversion of $\mathbf{1}$ and the degree of degradation of primary photoproducts on the subsequent irradiation was assessed by integration of individual IR peaks.

Laser Flash Photolysis. A Nd:YAG laser (Spectra Physics LAB-150-10, $266 \mathrm{~nm}, 5 \mathrm{~ns}, 30 \mathrm{~mJ}$ ) was used as the excitation light source. The spectrometer has been described previously. ${ }^{12}$ Solutions were prepared in dry spectroscopic grade hexane to an optical density (OD) of about 1.0 at $266 \mathrm{~nm}$. Experiments were performed at room temperature ( $295 \pm 1 \mathrm{~K})$. The sample solutions were changed after every laser shot.

Quantum Chemical Calculations. The geometries and harmonic vibrational frequencies of $\mathbf{1}$ and presumed intermediates of its photolysis were calculated by the B3LYP ${ }^{13,14}$ density functional method using the $6-31 \mathrm{G}(\mathrm{d})$ and $6-311 \mathrm{G}(\mathrm{df}, \mathrm{p})$ basis sets, with the Gaussian- $03^{15}$ suite of programs. All equilibrium structures were ascertained to be minima on the potential-energy surfaces. The harmonic frequencies calculated by B3LYP/6$311 \mathrm{G}(\mathrm{df}, \mathrm{p})$ were scaled by the factor of 0.98 (for $\mathrm{SN}$ heterocyclic compounds) or 0.97 (for acyclic species) for their use in assigning the experimental IR spectra.

Excited-state energies of $\mathbf{1}$ and proposed intermediates were calculated at the B3LYP/6-311G(df,p) geometries by the CASSCF/CASPT2 procedure $^{16}$ with the ANO-S basis set of Pierloot et al. ${ }^{17}$ using the MOLCAS program. ${ }^{18}$ In order to arrive at a satisfactory description of all excited states at the CASPT2 level (i.e., remove intruder states) it was necessary to resort to the level-shifting technique, ${ }^{19}$ whereby it was carefully ascertained that no artifacts are introduced.

\section{Results and Discussion}

It has been shown previously ${ }^{8}$ that photolysis of $\mathbf{1}$ at ambient temperature yields the persistent radical $\mathbf{2}$ in nearly quantitative yield (>95\%), whereas photolysis of $\mathbf{1}$ in low-temperature matrices results in the formation of products showing strong absorptions at the blue edge of the visible spectrum. ${ }^{10} \mathrm{We}$ found that room-temperature laser flash photolysis of $\mathbf{1}$ in hexane produces a transient UV-vis spectrum (Figure 1, spectrum 1), which nearly congruent with the difference UV-vis spectrum formed upon steady state photolysis of $\mathbf{1}$ in an argon matrix at $12 \mathrm{~K}$ (spectrum 2), although the absorption band around 300 $\mathrm{nm}$ is slightly shifted to the red.

On the basis of this similarity we propose that the products formed upon photolysis of $\mathbf{1}$ in an argon matrix are similar to

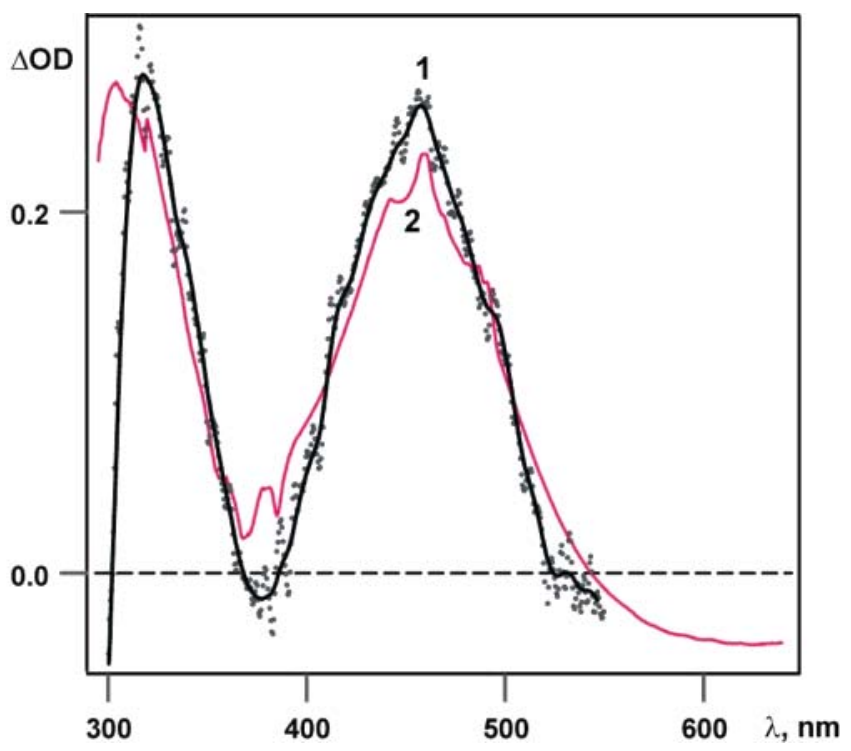

Figure 1. Transient absorption spectrum detected $20 \mathrm{~ns}$ after the laser excitation (266 nm, $30 \mathrm{~mJ}, 5 \mathrm{~ns}$ ) of 1,3,2,4-benzodithiadiazine (1) at $295 \mathrm{~K}$ (spectrum 1, averaged over 20 shots, multiplied by 9) and differential absorption spectrum recorded in argon matrix upon irradiation at $313 \mathrm{~nm}$ for $5 \mathrm{~min}(2)$.

the intermediates of its photolysis at ambient temperature. Therefore, revealing the nature of these species will be invaluable for understanding the mechanism of the formation of radical $\mathbf{2}$ at ambient temperature.

As we wanted to assign the experimental IR and UV-vis spectra detected upon photolysis of $\mathbf{1}$ in argon matrices by means of quantum chemical calculations, we began by testing the accuracy and reliability of the methods we intended to use by reproducing the IR and UV-vis spectra of benzodithiadiazine 1. Figure $2 \mathrm{~A}$ shows that the calculated IR spectrum of $\mathbf{1}$ is in very good agreement with the experimental one. Figure $2 \mathrm{~B}$ shows that some of the UV-vis maxima calculated by the CASSCF/CASPT2 procedure are noticeably shifted to the red, especially the long-wavelength maximum (see also Table S1 in Supporting Information). Nevertheless calculations reproduce the UV-vis spectrum of $\mathbf{1}$ quite satisfactorily. Therefore it appears that this computational protocol can be used with confidence for spectral assignments of SN heterocycles. Nevertheless, our assignments are based mainly on the IR spectroscopic data.

The quantum yield of 1,3,2,4-benzodithiadiazine photodecomposition at room temperature depends strongly on the excitation wavelength: it is reduced from 0.08 at $313 \mathrm{~nm}$ to $3.6 \times 10^{-3}$ at $365 \mathrm{~nm}$ and to less than $3 \times 10^{-4}$ at $436 \mathrm{~nm} .{ }^{8} \mathrm{~A}$ similar wavelength dependence was observed at cryogenic temperatures. We were unable to decompose $\mathbf{1}$ using light in the range of 425-700 $\mathrm{nm}$, whereas a comparable amount of $\mathbf{1}$ was decomposed on excitation at $365 \mathrm{~nm}$ for $2 \mathrm{~h}$ and at 313 $\mathrm{nm}$ for $5 \mathrm{~min}$ although the optical densities of the samples at the excitation wavelengths (313 and $365 \mathrm{~nm})$ were similar $(0.9$ and 1.2). Note that in the spectrum of mercury lamps the intensity of $365 \mathrm{~nm}$ line is even higher than that of the $313 \mathrm{~nm}$ line. ${ }^{20}$

The matrix UV-vis spectra recorded after photolysis of $\mathbf{1}$ at 313 and $365 \mathrm{~nm}$ differ noticeably in the visible region (Figure 3 , spectra 1 and 2). The latter spectrum is characterized by a broad band with a maximum at $460 \mathrm{~nm}$ and a narrow peak at $\sim 490 \mathrm{~nm}$. Figure 4 illustrates the corresponding changes in the IR spectrum of $\mathbf{1}$. It shows that very similar sets of new peaks, differing only in their relative intensities, are formed upon 


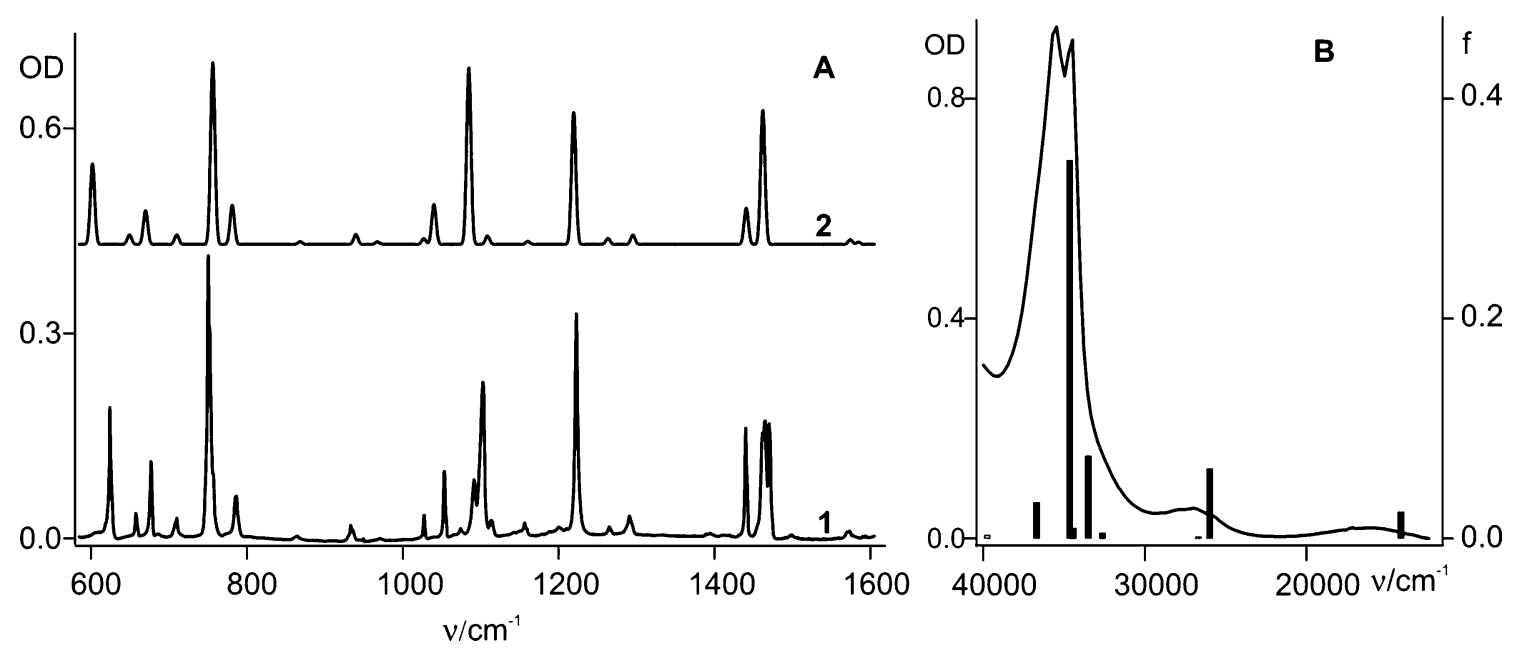

Figure 2. (A) Experimental IR spectrum of 1,3,2,4-benzodithiadiazine 1 in argon matrix at $12 \mathrm{~K}$ (1) and its simulation by the B3LYP/6-311G(df,p) method with a scaling factor of 0.98 (2). (B) UV-vis spectrum of 1 in hexane at $295 \mathrm{~K}$. The vertical bars indicate the positions and oscillator strengths of electronic transitions calculated by the CASSCF(16,12)/CASPT2/ANO-S method at the B3LYP/6-311G(df,p) geometry of 1.

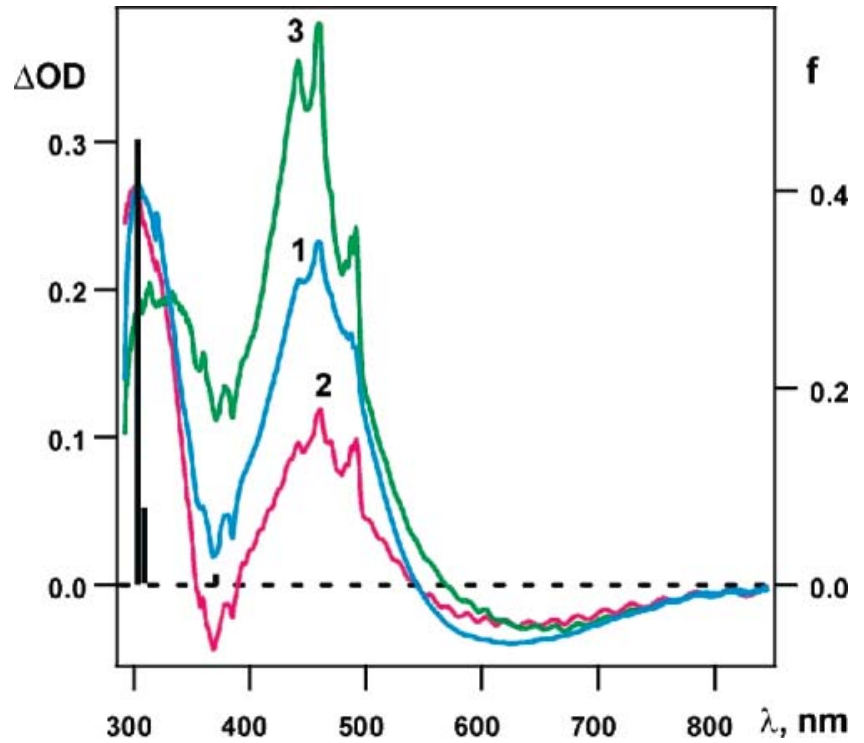

Figure 3. Difference UV-vis spectra detected after photolysis of 1 at $313 \mathrm{~nm}$ for $5 \mathrm{~min}$ (1) and at $365 \mathrm{~nm}$ for $90 \mathrm{~min}$ (2) and 20 additional minutes of $313 \mathrm{~nm}$ irradiation (3) in an Ar matrix at $12 \mathrm{~K}$. The solid vertical lines indicate the calculated positions and relative oscillator strengths of the electronic transitions of thiazyl 3 (CASSCF $(16,12) /$ CASPT2/ANO-S at the B3LYP/6-311G(df,p) geometry).

photolysis of 1 at 313 (spectrum 1) and $365 \mathrm{~nm}$ (spectrum 2). For instance, photolysis at $365 \mathrm{~nm}$ gives rise to a more intense peak at $1344 \mathrm{~cm}^{-1}$ and slightly less intense peaks at 1492, 1498 , and $1527 \mathrm{~cm}^{-1}$ than photolysis at $313 \mathrm{~nm}$. These differences in the IR and UV spectra of products are indicative of the formation of more than one species on photolysis of $\mathbf{1}$ in an argon matrix.

Indeed, irradiation at $313 \mathrm{~nm}$ of the sample photolyzed previously at $365 \mathrm{~nm}$ led to the disappearance of the most intense IR peaks at 1344 and $1443 \mathrm{~cm}^{-1}$ (spectrum 3, Figure 4 ), whereas some other IR bands continued to grow. Figure 4 shows that these intense peaks and also a series of less intense ones $\left(746,816,931,1026\right.$, and $1128 \mathrm{~cm}^{-1}$, spectrum 2) correlate well with the calculated spectrum of thiazyl 3 (spectrum 4). Unfortunately the decrease of the less intense peaks in the spectrum 3 is not evident, although small negative features could be found on detailed examination.

Thiazyl 3 (Chart 2) is an isomer of dithiadiazine 1, which has the same five-membered heterocyclic moiety as the final

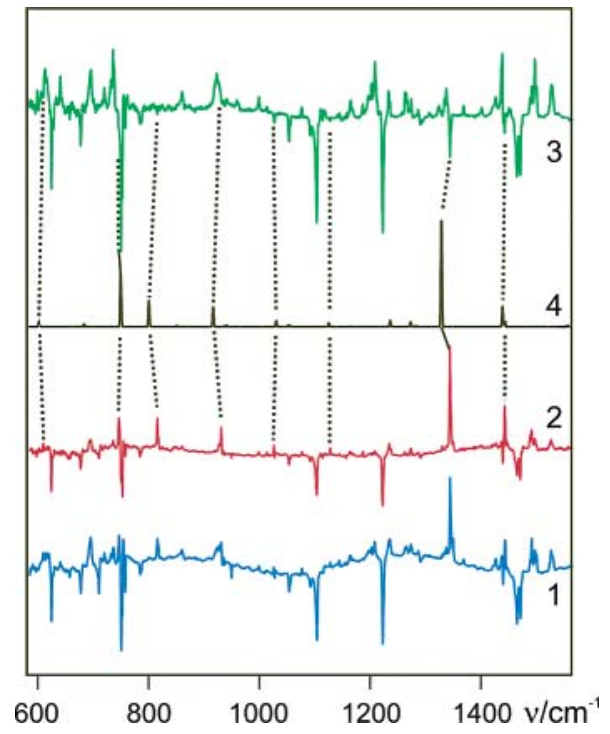

Figure 4. IR difference spectra obtained after photolysis of $\mathbf{1}$ at 313 $\mathrm{nm}$ for $5 \mathrm{~min}(1)$, at $365 \mathrm{~nm}$ for $90 \mathrm{~min}$ (2), and 20 additional minutes of $313 \mathrm{~nm}$ irradiation (3) in an Ar matrix at $12 \mathrm{~K}$. (4) IR spectrum of thiazyl 3 calculated by the B3LYP/6-311G(df,p) method with a scaling factor 0.98 .

radical 2. In our preliminary study ${ }^{10}$ the intermediate $\mathbf{3}$ was considered as a nitrenoid species with a structure intermediate between the nitrene $\mathrm{RS}-\mathrm{N}$ : and the thiazyl $\mathrm{RS} \equiv \mathrm{N}$. However the calculated length of the exocyclic SN bond $(1.467 \AA)$ is typical of an SN triple bond. ${ }^{21-24}$ For instance, in thiazyl fluorides $\mathrm{FS} \equiv \mathrm{N}$ and $\mathrm{F}_{3} \mathrm{~S} \equiv \mathrm{N}$ the $\mathrm{SN}$ bond length, according to the data from microwave spectroscopy, is equal to 1.448 and $1.416 \AA$, respectively, ${ }^{21,22}$ whereas in the thiazylamide anions $\mathrm{R}-\mathrm{N}-\mathrm{S} \equiv \mathrm{N}$ ( $\mathrm{R}=\mathrm{Ar}$, Alk), according to $\mathrm{X}$-ray diffraction analysis, it ranges from 1.442 to $1.490 \AA .{ }^{23,24}$ Note, that the calculated length of heterocyclic SN bond $(1.577 \AA)$ is quite typical of a double bond, ${ }^{1 \mathrm{a}, 25}$ while the heterocyclic SS bond $(2.19 \AA)$ is predicted to be slightly longer than a typical single bond $(2.05 \pm 0.05 \AA){ }^{26}$

It is evident from Figure 3 (spectrum 3 ) that secondary 313$\mathrm{nm}$ photolysis leads to a significant growth of the band intensities in the visible region, whereas the UV band grows much less than initially. We have calculated the UV-vis spectrum of the thiazyl 3 by the CASSCF/CASPT2 method (Figure 3, Table S2) which predicts that this species exhibits 


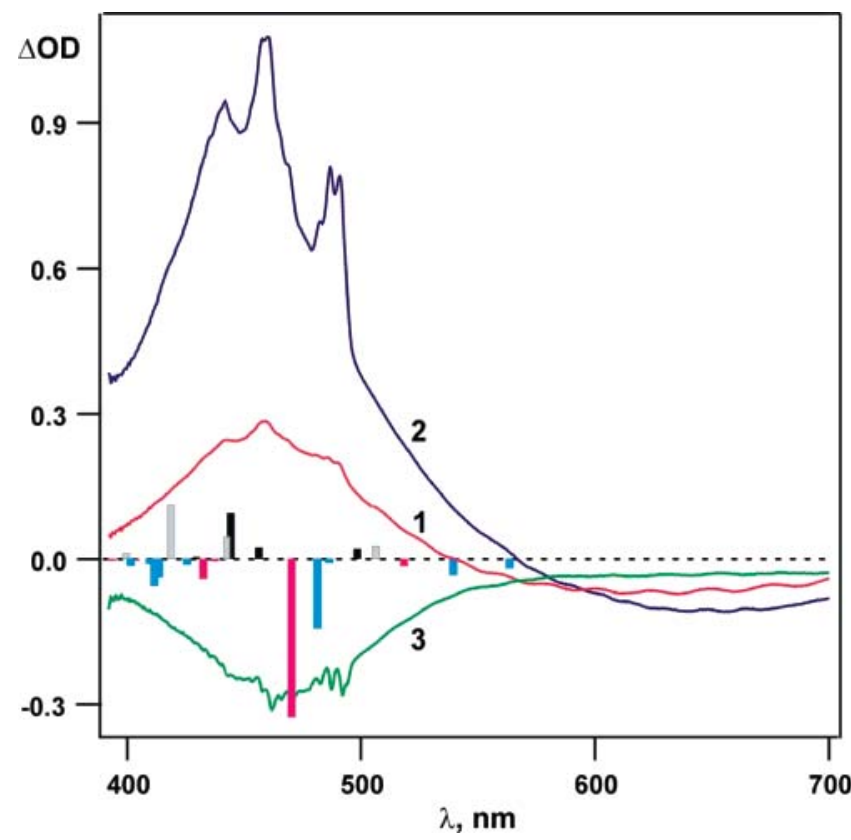

Figure 5. Difference spectra detected upon photolysis of 1 at $313 \mathrm{~nm}$ for $10 \mathrm{~min} \mathrm{(1),} 90 \mathrm{~min} \mathrm{(2),} \mathrm{and} 30$ additional minutes at $>515 \mathrm{~nm} \mathrm{(3)}$ in an argon matrix at $12 \mathrm{~K}$. The vertical bars indicate the calculated positions and relative oscillator strengths of the electronic transitions of the o-quinoid acyclic compounds 6 (blue) and 7 (red) and of two rotamers of the four-membered heterocyclic species $\mathbf{8}$ (black and gray bars, $\operatorname{CASSCF}(16,12) / C A S P T 2 / A N O-S$ excited-state calculations at B3LYP/6-311G(df,p) geometries).

strong absorption bands in the near UV region with maxima at $304 \mathrm{~nm}$ (with a very high oscillator strength $f=0.45$ ) and at $307 \mathrm{~nm}(f=0.075)$. Weaker transitions are predicted at 371 $\mathrm{nm}(f=0.01)$ and $385 \mathrm{~nm}\left(f=1.7 \times 10^{-4}\right)$ and a very weak transition at $546 \mathrm{~nm}\left(f=1.2 \times 10^{-5}\right)$. Therefore, we believe that the absorption band peaking at ca. $300 \mathrm{~nm}$ belongs mainly to thiazyl $\mathbf{3}$ which should contribute negligibly to the visible spectrum, whereas the bands above $400 \mathrm{~nm}$ belong to one or several other products (Figure 3). This is why subsequent photolysis at $313 \mathrm{~nm}$, which decomposes $\mathbf{3}$, leads to significant growth of the visible band with the maximum at ca. $460 \mathrm{~nm}$.

The sharp band at $490 \mathrm{~nm}$ arises not only on $365 \mathrm{~nm}$ photolysis (Figure 3) but more pronouncedly on prolonged irradiation at $313 \mathrm{~nm}$ (Figure 5, spectrum 2). Hence this band is probably due to a secondary photolysis product (4), which is not yet identified. As the quantum yield of photolysis of $\mathbf{1}$ at $365 \mathrm{~nm}$ is very small, this secondary product $\mathbf{4}$ appears already during the initial stages of the photodecomposition of $\mathbf{1}$ at this wavelength (Figure 3).

Subsequent irradiation of the sample at $>515 \mathrm{~nm}$ leads to the bleaching of the broad band peaking at $460 \mathrm{~nm}$ (Figure 5, spectrum 3), although the sharp features at 488 and $492 \mathrm{~nm}$ that belong to the secondary product 4 are also affected. In the IR spectrum (Figure 6A, spectrum 2) irradiation at $>515 \mathrm{~nm}$ leads to the decrease of some peaks and to the growth of others, while the bands of thiazyl $\mathbf{3}$ (marked by asterisks) remain unchanged. The latter observation agrees with the fact that $\mathbf{3}$ has no pronounced absorption in the visible region.

It is reasonable to assume that the primary process in the photochemistry of $\mathbf{1}$ is the cleavage of the SN single bond which leads to the formation of biradical $\mathbf{5}$ (Scheme 1). The intermediate $\mathbf{5}$ can undergo cyclization to the thiazyl $\mathbf{3}$ or relaxation to the $o$-quinoid acyclic products 6 and 7. Cyclization to a thiazabenzocyclobutene $\mathbf{8}$ is also possible (Scheme 1).

Interestingly, structures resembling those of $\mathbf{6}$ and 7 have recently been observed by $X$-ray diffraction for $X \cdots X(X=S$, $\mathrm{Se}$ ) bonded dimers of some 1,2,3-dithiazolyl and -thiaselenazolyl radicals in the solid state. ${ }^{27}$

The calculated IR spectra of compounds $\mathbf{6}-\mathbf{8}$ correlate satisfactorily with the experimental spectra detected upon irradiation at the indicated wavelengths (Figure 6A). It is clear from Figure 6B that two different products contribute to the doublet at 1492 and $1498 \mathrm{~cm}^{-1}$. The former peak belongs to the product the relative yield of which diminishes upon prolonged photolysis (Figure 6B, spectra 1-3). Two other peaks, at 1498 and $1528 \mathrm{~cm}^{-1}$, belong to the second product, as both of them were bleached on subsequent

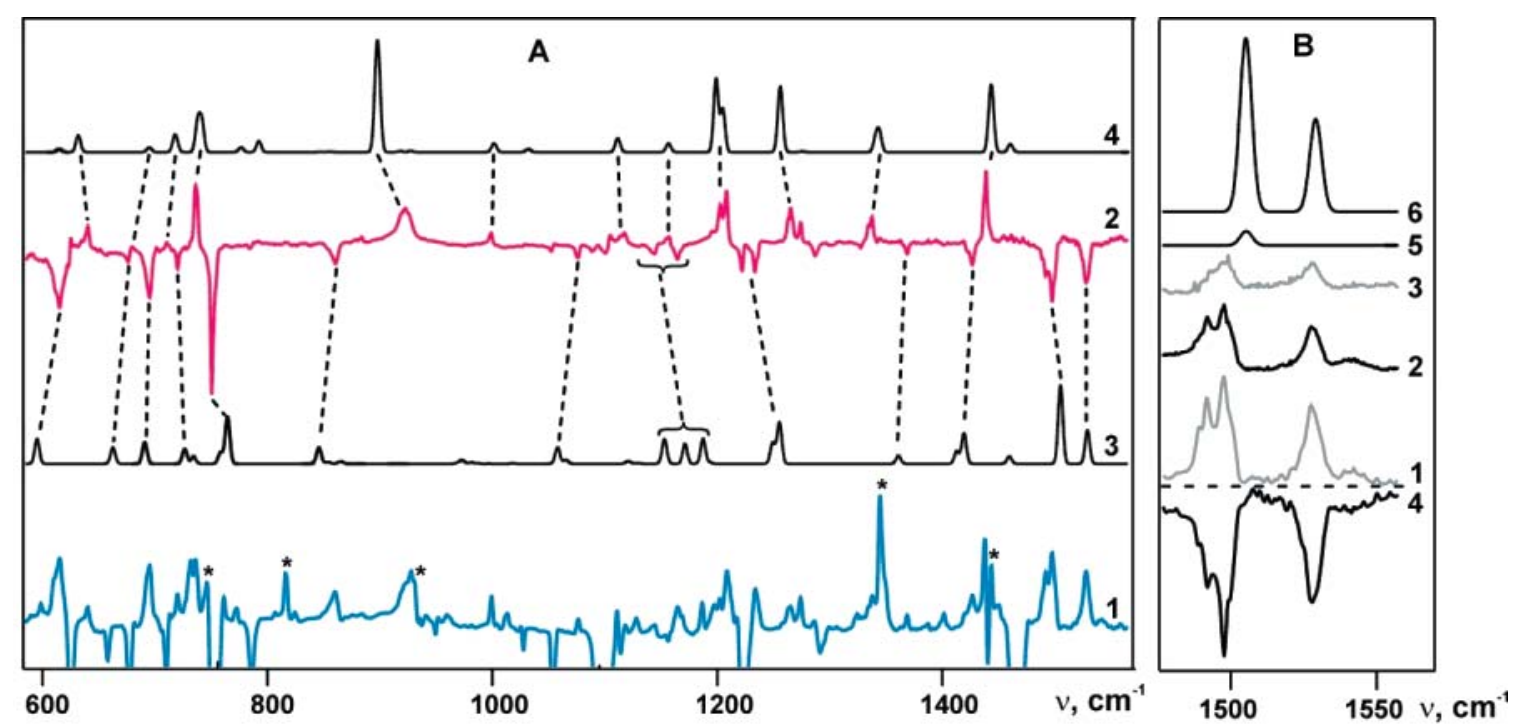

Figure 6. (A) Difference IR spectra detected after photolysis of $\mathbf{1}$ at $313 \mathrm{~nm}$ for $90 \mathrm{~min}$ (blue trace 1) and 30 additional minutes at $>515 \mathrm{~nm}$ (red trace 2) in an Ar matrix at $12 \mathrm{~K}$ (the IR peaks of $\mathbf{3}$ are marked by asterisks). Trace 3 shows the sum of the IR spectra of compounds $\mathbf{6}$ and $\mathbf{7}$ in a ratio of 3:1, calculated by B3LYP/6-311G(df,p) (scaling factor 0.97), and trace 4 shows the sum of the IR spectra of a $1: 1$ mixture of two rotamers of $\mathbf{8}$, calculated by the same procedure (scaling factor 0.98). (B) Changes in the region around $1500 \mathrm{~cm}^{-1}$ after $10 \mathrm{~min}$ (1), $30 \mathrm{~min}$ (2), and $60 \mathrm{~min}$ of irradiation at $313 \mathrm{~nm}$ and finally after $30 \mathrm{~min}$ of irradiation at $>515 \mathrm{~nm}$ (4). Traces 5 and 6 show the calculated spectra of compounds 6 and 7 , respectively. 


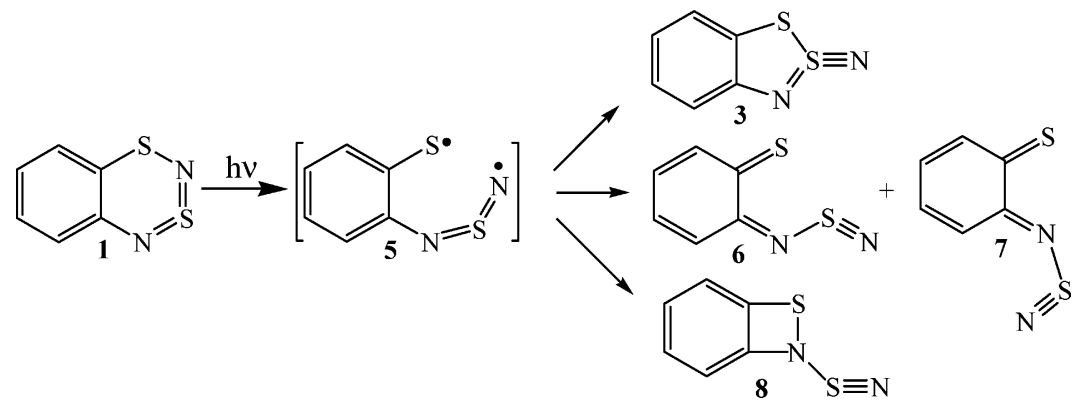

TABLE 1: Vertical Excitation Energies Calculated for $o$-Quinoid Acyclic Species 6 and 7 Using the CASSCF $(16,12) / C A S P T 2 / A N O-S$ Method at the B3LYP/ 6-311G(df,p) Geometry

\begin{tabular}{rrrr} 
& & \multicolumn{2}{c}{$\mathbf{7}$} \\
\cline { 3 - 4 }$\lambda / \mathrm{nm}$ & $f \times 10^{3}$ & $\lambda / n m$ & $f \times 10^{3}$ \\
\hline 2315 & 0.4 & 1802 & 0.3 \\
1214 & 0.4 & 1203 & 0.1 \\
701 & 0.5 & 674 & 0.4 \\
564 & 4.6 & 519 & 3.3 \\
540 & 7.9 & 478 & 0.1 \\
487 & 1.7 & 471 & 81.4 \\
482 & 35.5 & 438 & 0.8 \\
426 & 2.7 & 433 & 9.9 \\
414 & 9.1 & 404 & 0.6 \\
412 & 13.5 & 394 & 0.6 \\
410 & 2.2 & 384 & 0.4 \\
402 & 3.0 & 379 & 6.4 \\
385 & 4.8 & 349 & 4.1 \\
366 & 0.4 & 337 & 0.2 \\
323 & 3.7 & 333 & 70.8 \\
320 & 43.8 & 317 & 112.1 \\
318 & 4.5 & 297 & 21.4 \\
296 & 0.5 & 284 & 2.6
\end{tabular}

irradiation at $>515 \mathrm{~nm}$ (Figure 6B, spectrum 4). We assigned the peak at $1492 \mathrm{~cm}^{-1}$ to $\mathbf{6}$ and the latter two to 7 . The other IR peaks that are bleached upon irradiation at $>515 \mathrm{~nm}$ (Figure $6 \mathrm{~A}$, spectrum 2 , negative peaks) are reproduced fairly well by the calculated spectra of $\mathbf{6}$ and $\mathbf{7}$, if these species are assumed to be formed in a ratio of about 3:1 (the separate calculated IR spectra of $\mathbf{6}$ and $\mathbf{7}$ are reproduced in the Supporting Information, Figure S1).

The IR spectrum formed on subsequent photolysis at $>515$ $\mathrm{nm}$ (Figure 6A, spectrum 2, positive peaks) is in very good agreement with the calculated spectrum of thiazabenzocyclobutene $\mathbf{8}$, if one assumes that the two rotamers, 8a and $\mathbf{8 b}$ (Chart 3), are formed in equal amounts (spectrum 4).

\section{CHART 3}<smiles>N#Sn1sc2ccccc21</smiles>

$8 \mathbf{a}$

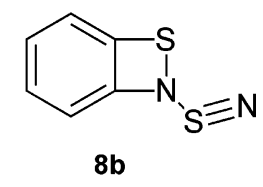

The situation with regard to the assignment of the UV-vis spectra of products $\mathbf{6}-\mathbf{8}$ is less straightforward. The positions and oscillator strengths of the electronic transitions in the spectra of $\mathbf{6}, \mathbf{7}, \mathbf{8} \mathbf{a}$, and $\mathbf{8 b}$ calculated by the $\operatorname{CASSCF}(16,12) / C A S P T 2$ procedure are depicted schematically in Figure 5 and listed in Tables 1 and 2 (details are in the Supporting Information, Tables S3-S6). Calculations predict that $\mathbf{6}-\mathbf{8}$ have intense transitions in the visible region with maxima at $482 \mathrm{~nm}\left(f=3.6 \times 10^{-2}\right)$
TABLE 2: Vertical Excitation Energies Calculated for Four-Membered Heterocyclic Species 8a and 8b Using the CASSCF $(16,12) / C A S P T 2 / A N O-S$ Method at the B3LYP/ 6-311G(df,p) Geometry

\begin{tabular}{|c|c|c|c|}
\hline \multicolumn{2}{|c|}{$8 \mathbf{a}$} & \multicolumn{2}{|c|}{$8 b$} \\
\hline$\lambda / \mathrm{nm}$ & $f \times 10^{3}$ & $\lambda / n m$ & $f \times 10^{3}$ \\
\hline 499 & 10.0 & 507 & 13.0 \\
\hline 457 & 12.0 & 444 & 23.0 \\
\hline 444 & 48.0 & 419 & 56.0 \\
\hline 430 & 2.0 & 400 & 5.6 \\
\hline 365 & 48.0 & 348 & 63.0 \\
\hline 319 & 24.0 & 322 & 7.6 \\
\hline 316 & 100.0 & 314 & 97.0 \\
\hline 275 & 47.0 & 273 & 55.0 \\
\hline 274 & 3.0 & 270 & 5.6 \\
\hline
\end{tabular}

for $\mathbf{6}$, at $471 \mathrm{~nm}\left(f=8.1 \times 10^{-2}\right)$ for $\mathbf{7}$, and at about 500 and $450 \mathrm{~nm}$ for $\mathbf{8} \mathbf{a}$ and $\mathbf{b}$. It is obvious that all predicted transitions are close to the maximum of the experimental absorption band at $460 \mathrm{~nm}$. Tables 1 and 2 show that $\mathbf{6}-\mathbf{8}$ have also intense transitions in the near-UV region with maxima at about 300$330 \mathrm{~nm}\left(f=10^{-2}-10^{-1}\right)$. However, their intensities are not so pronounced as that of the main bands of $\mathbf{3}(304 \mathrm{~nm}, f=0.45$; $307 \mathrm{~nm}, f=0.075$ ).

Note, that $\mathbf{8 a}$ and $\mathbf{8 b}$ are predicted to have also intense transitions at 365 or $348 \mathrm{~nm}$ (Table 2). This agrees well with the growth of the absorption around $350-370 \mathrm{~nm}$ on prolonged irradiation at $313 \mathrm{~nm}$ (e.g., Figure 3, spectrum 3), which is accompanied by the formation of considerable amount of $\mathbf{8}$ along with 6 and 7 (Figure 4, spectrum 3).

Table 2 and Figure 5 show that the transitions predicted for $8 \mathbf{a}$ and $\mathbf{8 b}$ in the visible region are less intense and shifted to the blue relative to the most intense bands of $\mathbf{6}$ and 7. This could be the reason why we observed only a net decrease of the visible absorptions on $>515 \mathrm{~nm}$ irradiation, although according to the IR spectra (Figure 6A) this decrease was accompanied by the transformation of $\mathbf{6}$ and $\mathbf{7}$ to $\mathbf{8}$.

The photochemistry of $\mathbf{1}$ in argon matrices is even more complicated than discussed above. By use of very low concentrations of 1 and effecting excitation at $285 \mathrm{~nm}$, where the absorption of $\mathbf{1}$ has a maximum (Figure 2B), it was possible to decompose ca. $80 \%$ of $\mathbf{1}$. The estimation was done using the IR band at $1103 \mathrm{~cm}^{-1}$ and the doublet at 1465 and $1471 \mathrm{~cm}^{-1}$. Subsequent $5 \mathrm{~min}$ irradiation of the resulting sample at $313 \mathrm{~nm}$ leads to a reduction of the IR bands assigned to $\mathbf{3}$ and $\mathbf{7}$ but, unexpectedly, to a partial recovery of the IR spectrum of benzodithiadiazine 1 (Figure 7A,B). At that irradiation about $70 \%$ of intermediate 3 and ca. $50 \%$ of intermediate 7 were decomposed, although only about $25 \%$ of the starting material 1 was recovered. Unfortunately the IR spectra of such samples were so weak that only the most intense peaks assigned above to 3 and 7 could be discerned (Figure 7B, spectrum a). 

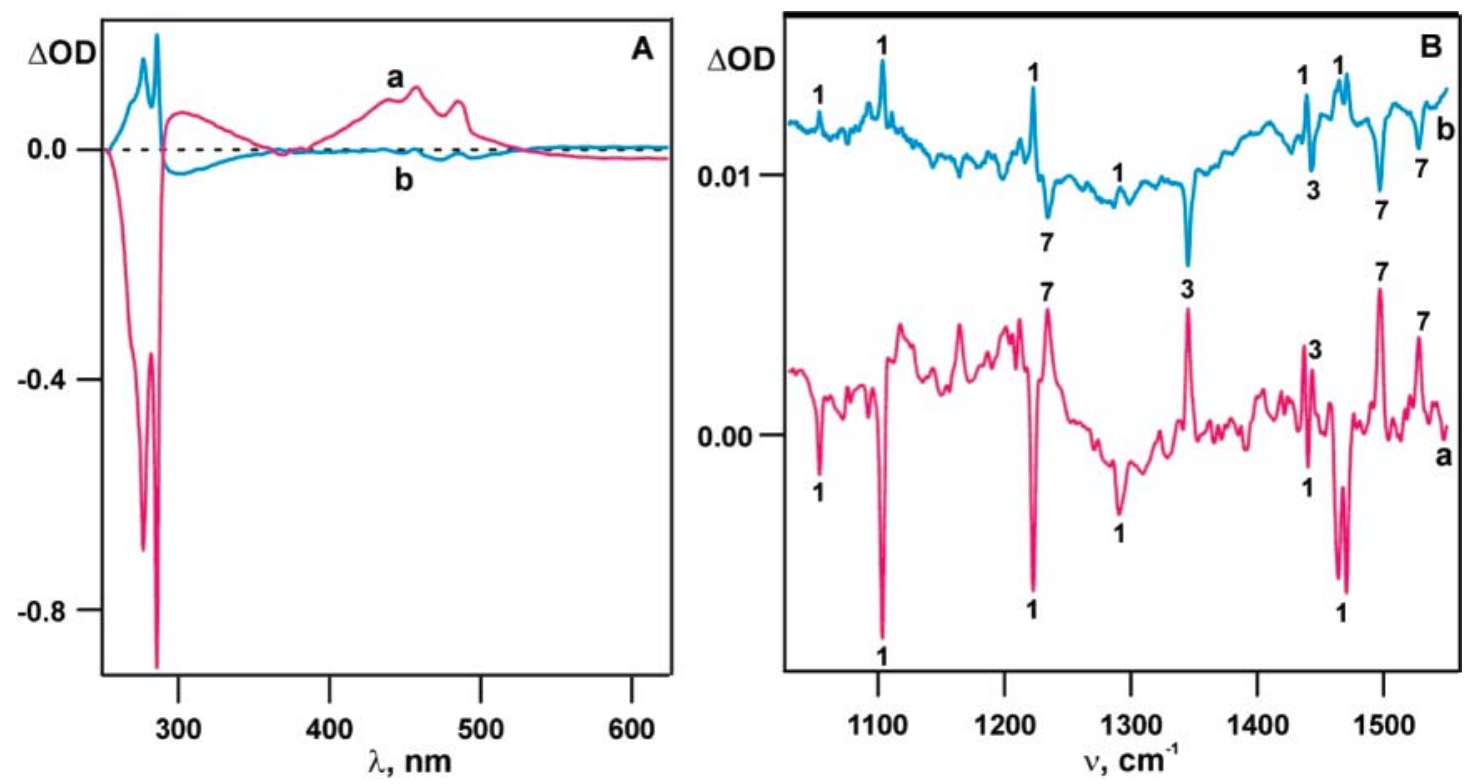

Figure 7. UV-vis (A) and IR difference spectra (B) obtained upon photolysis of $\mathbf{1}$ at $285 \mathrm{~nm}$ for 15 min (red spectra a) and upon subsequent irradiation at $313 \mathrm{~nm}$ for $5 \mathrm{~min}$ (blue spectra $\mathrm{b}$ ) in an argon matrix at $12 \mathrm{~K}$. The most prominent peaks are labeled with the numbers of species they are thought to belong to.

SCHEME 2: Photolysis of 1,3,2,4-Benzodithiadiazine in Argon Matrices at $12 \mathrm{~K}$

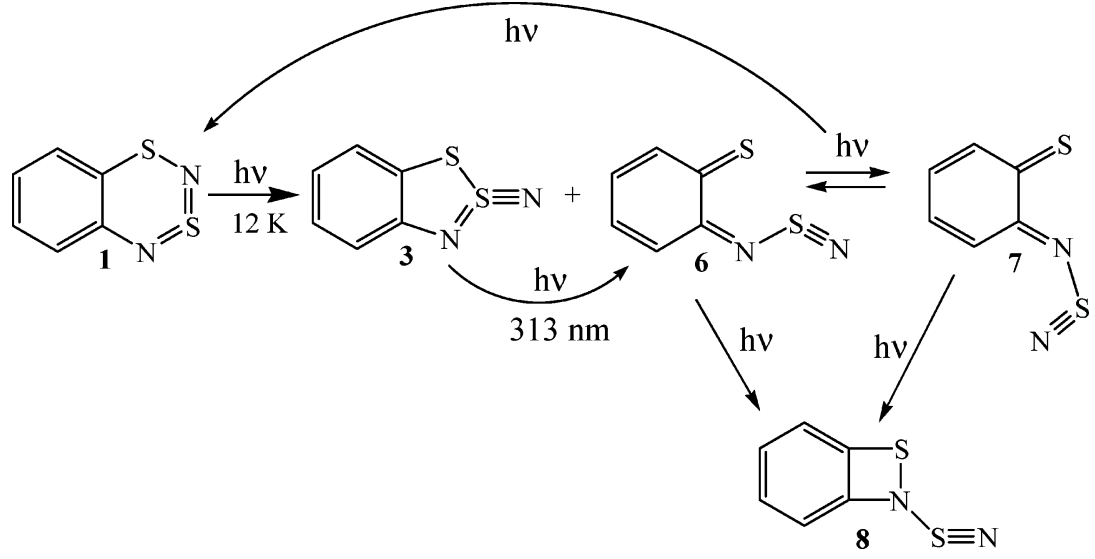

Additional irradiation at $313 \mathrm{~nm}$ for $25 \mathrm{~min}$ did not lead to noticeable changes in the UV-vis spectrum. However subsequent irradiation at $>375 \mathrm{~nm}$ for 30 min led to the recovery of about $20 \%$ more 1 . Thus we conclude that the photochemical transformation of $\mathbf{1}$ is reversible and that, after longer irradiation, a wavelength-dependent photostationary equilibrium is established.

The above-described experiments indicate that at least four products are formed during the initial stages (up to ca. 5\% conversion) of the 313-nm photolysis of $\mathbf{1}$ in argon matrices: a five- (3) and a four-membered (8) heterocyclic compound and two $o$-quinoid species (6 and 7). The formation of $\mathbf{3}$ and $\mathbf{6}$ stops after ca. $15-20 \%$ of $\mathbf{1}$ have been bleached. Conversely, the growth of $\mathbf{7}$ continues, while that of $\mathbf{8}$, which is initially very low, increases significantly on prolonged irradiation.

Thus the predominant primary products of the photolysis of $\mathbf{1}$ in argon matrices are compounds $\mathbf{3}$ and $\mathbf{6}$. On continued irradiation these products undergo further transformation (Scheme 2 ). In particular, we found (Figure 6A) that compounds 6 and 7 undergo cyclization to $\mathbf{8}$ even on long-wavelength ( $>515 \mathrm{~nm}$ ) irradiation. The same photoreaction should be responsible for the formation of $\mathbf{8}$ on prolonged irradiation of the sample at $313 \mathrm{~nm}$.
Prolonged irradiation of the sample at $313 \mathrm{~nm}$ leads also to the decomposition of $\mathbf{3}$ and, most probably, to the formation of 6 and 7, although formation of some unidentified products cannot be excluded. It is obvious that the $o$-quinoid compounds 6 and 7 can interconvert by photochemical cis-trans isomerization around the $\mathrm{C}=\mathrm{N}$ double bond. It cannot be excluded that excitation of $\mathbf{8}$ at $365 \mathrm{~nm}$ leads to $\mathrm{S}-\mathrm{N}$ bond cleavage and formation of $\mathbf{6}$ and 7, along with unidentified product(s). We could not demonstrate this experimentally; however, the absence of product $\mathbf{8}$ upon $365 \mathrm{~nm}$ photolysis of $\mathbf{1}$ could be an indication of its efficient decomposition.

It is clear from the comparison of the transient absorption spectra obtained at ambient temperature (Figure 1, spectrum 1) with the matrix spectrum (Figure 1, spectrum 2) that at least three intermediates $(\mathbf{3}, \mathbf{6}$, and 7$)$ are formed upon photolysis at room temperature and these should be accounted for in future analysis of laser flash photolysis experiments.

Figure 8 gives a preliminary account of the thermochemistry of the observed transformations (summary of calculations in the Supporting Information, Table S7). It shows that isomers $\mathbf{3}$ and 6-8 lie significantly higher in energy than the starting compound $\mathbf{1}$, but that they are very close in energy among themselves. In spite of the high exothermicity 


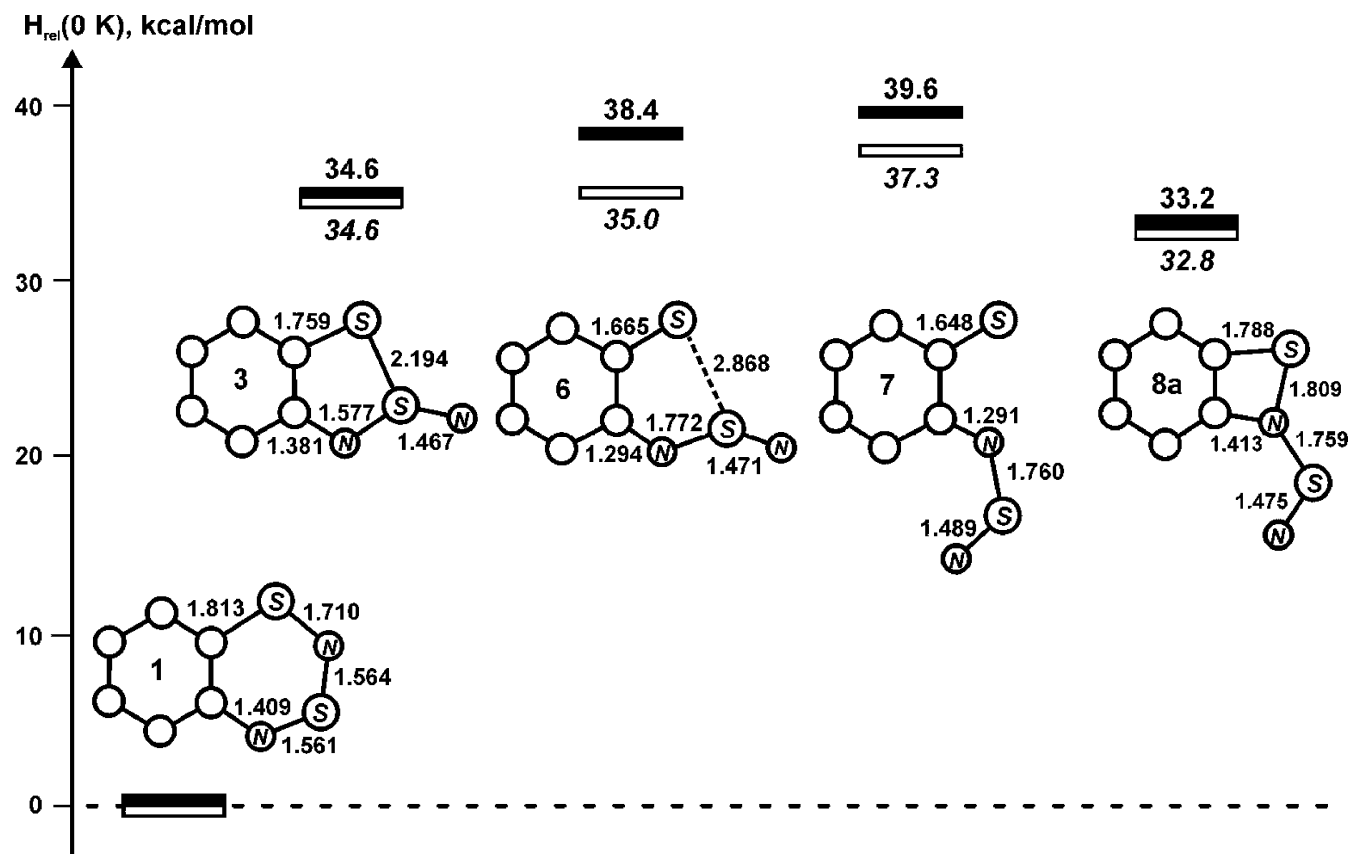

Figure 8. Selected bond lengths (in angstroms) and relative enthalpies (in kcal/mol) of the intermediates involved in the photoisomerization of 1,3,2,4-benzodithiadiazine 1. The bond lengths and the solid bars refer to B3LYP calculations with 6-311G(df,p) basis set; the open bars refer to the same calculations with $6-31 \mathrm{G}(\mathrm{d})$ basis set.

of the reversal of $\mathbf{6}$ and $\mathbf{7}$ to $\mathbf{1}$, light is needed to induce this reaction in $\mathrm{Ar}$ matrices. Calculations predict that the heterocyclic isomers $\mathbf{3}$ and $\mathbf{8}$ are somewhat lower in energy than the $o$-quinoid species $\mathbf{6}$ and 7. However the latter are unambiguously formed upon photolysis, both at room temperature and in cryogenic matrices. More detailed results of calculations, including activation energies for the interconversion of the different species in their singlet and triplet states and their excited-state reactivity will be presented in a forthcoming publication.

\section{Conclusions}

The chemistry of polysulfur-nitrogen (and chalcogennitrogen in general) heterocycles is a new area of heteroatom chemistry. Nevertheless, many novel compounds have already been prepared and these are found to feature unusual structures and reactivities, which cannot readily be accounted for within the framework of classical chemical theories. In particular, the mechanistic aspects of polysulfur-nitrogen heterocyclic chemistry remain largely unexplored mainly due to the limited amount of information that can be obtained from conventional spectroscopic techniques (for example, NMR) in this case.

In the present work we have studied the photochemical transformations of 1,3,2,4-benzodithiadiazine in argon matrices at $12 \mathrm{~K}$ using IR and UV-vis spectroscopy. Thereby, and with the help of quantum chemical calculations we were able to characterize four- and five-membered heterocyclic species ( $\mathbf{8}$ and $\mathbf{3}$ ) as well as $\boldsymbol{o}$-quinoid species $\mathbf{6}$ and $\mathbf{7}$. We found that all these isomeric intermediates as well as starting compound 1 can be interconverted by irradiation at selected wavelengths.

Acknowledgment. The authors are grateful to the Russian Foundation for Basic Research (Project 04-03-32259), the Siberian Branch of the Russian Academy of Sciences (interdisciplinary project N25), and Swiss National Science Foundation (project No 200020-105217). We thank Professor M.S. Platz at The Ohio State University for the opportunity to use their laser flash photolysis setup. A.M. and A.Z. thank the Council for the President of Russian Federation Grants for Young Scientists and Their Supervisors (Grant MK-3178.2005.3), and A.M. thanks the National Science Support Foundation (Russia) for a postdoctoral scholarship.

Supporting Information Available: Cartesian coordinates of all stationary points located in this study and details of CASSCF/CASPT2 calculations (text file). UV-vis spectra of dithiadiazine 1, thyazil 3, $o$-quinoid acyclic intermediates 6 and 7, and thiazacyclobutenes $\mathbf{8 a}$ and $\mathbf{8 b}$ calculated by CASSCF$(16,12) / C A S P T 2$ method (Tables S1-S6); calculated IR spectra of $\mathbf{6}, \mathbf{7}, \mathbf{8 a}$, and $\mathbf{8 b}$ (Figures $\mathrm{S} 1-\mathrm{S} 2$ ); calculations of the formation enthalpy of intermediates $\mathbf{3}, \mathbf{6}, \mathbf{7}$, and $\mathbf{8}$ and starting compound 1 by the B3LYP method with 6-31G(d) and 6-311G(d,p) basis sets (Table S7) (pdf file). This information is available free of charge via the Internet at http://pubs.acs.org.

\section{References and Notes}

(1) (a) Cordes, A. W.; Hojo, M.; Koenig, H.; Noble, M. C.; Oakley, R. T.; Pennington, W. T. Inorg. Chem. 1986, 25, 1137. (b) Rees, C. W. J. Heterocyclic Chem. 1992, 29, 639. (c) Torroba, T. J. Prakt. Chem. 1999, $341,99$.

(2) Chivers, T. A Guide to Chalcogen-Nitrogen Chemistry; World Scientific: New Jersey, 2005; p 330.

(3) (a) Rawson, J. M.; Luzon, J.; Palacio, F. Coord. Chem. Rev. 2005, 249, 2631. (b) Rawson, J. M.; Palacio, F. Struct. Bond. 2001, 100, 93. (c) Boere, R. T.; Roemmele, T. L. Coord. Chem. Rev. 2000, 210, 369-445. (d) Rawson, J. M.; McManus, G. D. Coord. Chem. Rev. 1999, 189, 135. (e) Rawson, J. M.; Banister, A. J.; Lavender, I. Adv. Heterocyclic Chem. 1995, 62, 137.

(4) (a) Ikorskii, V. N.; Irtegova, I. G.; Lork, E.; Makarov, A. Yu.; Mews, R.; Ovcharenko, V. I.; Zibarev, A. V. Eur. J. Inorg. Chem. 2006, 3061. (b) Beer, L.; Brusso, J. L.; Haddon, R. C.; Itkis, M. E.; Oakley, R. T.; Reed, R. W.; Richardson, J. F.; Secco, R. A.; Yu, X. Chem. Commun. 2005, 5745. (c) Makarov, A. Yu.; Irtegova, I. G.; Vasilieva, N. V.; Bagryanskaya, I. Yu.; Borrmann, T.; Gatilov, Yu. V. Lork, E.; Mews, R.; Stohrer, W.-D.; Zibarev, A. V. Inorg. Chem. 2005, 44, 7194. (d) Zienkiewicz, J.; Kaszynski, P.; Young, V. G. J. Org. Chem. 2004, 69, 7525; e) 
Beer, L.; Brusso, J. L.; Cordes, A. W.; Godde, E.; Haddon, R. C.; Itkis, M. E.; Oakley, R. T.; Reed, R. W. Chem. Commun. 2002, 2562.

(5) Banister, A. J.; Gorrell, I. B. Adv. Mater. 1998, 10, 1415.

(6) (a) Comprehensive Heterocyclic Chemistry II; Katritsky, A. R.; Rees, C. W.; Scriven, E. F. V. Ed. Pergamon Press: Oxford, 1996. (b) Comprehensive Heterocyclic Chemistry; Katritsky, A. R., Rees, C. W., Eds.; Pergamon Press: Oxford, 1984.

(7) Kirsch, G. 1,2,3-Benzodithiazolium-Salze. Methoden der Organische Chemie (Houben-Weyl; Schaumann, E., Ed.; Thieme: Stuttgart, 1994

(8) Vlasyuk, I. V.; Bagryansky, V. A.; Gritsan, N. P.; Molin, Yu. N.;

Makarov, A. Yu.; Gatilov, Yu. V.; Scherbukhin, V. V.; Zibarev, A. V. Phys. Chem. Chem. Phys. 2001, 3, 409.

(9) (a) Pavlik, J. W.; Changtong, C.; Tsefrikas, V. J. Org. Chem. 2003,

68, 4855. (b) Morris, J. L.; Rees, C. W. J. Chem. Soc. Perkin Trans. 1987, $1,217$.

(10) Gritsan, N. P.; Bagryansky, V. A.; Vlasyuk, I. V.; Molin, Yu. N.; Makarov, A. Yu.; Platz, M. S.; Zibarev, A. V. Russ. Chem. Bull. Int. Ed. 2001, 50, 2064.

(11) Bally, T. Matrix isolation. In Reactive Intermediate Chemistry Moss, R. A., Platz, M. S., Jones, M., Eds.; Wiley-Interscience: New York, 2004, p 797.

(12) Tsao, M.-L.; Gritsan, N. P., James, T. R.; Platz, M. S.; Hrovat, D.; Borden, W. T. J. Am. Chem. Soc. 2003, 125, 9343.

(13) Becke, A. D. J. Chem. Phys. 1993, 98, 5648.

(14) Lee, C.; Yang, W.; Parr, R. G. Phys. Rev. B 1988, 37, 785.

(15) Frisch, M. J. A., et al. Gaussian 03, revision B.01; Gaussian, Inc., Pittsburg, 2003 (full reference given in Supporting Information).

(16) (a) Roos, B. O. Adv. Chem. Phys. 1987, 69, 399. (b) Andersson, K.; Roos, B. O. In Modern Electronic Structure Theory; World Scientific Publishing Co.: Singapore, 1995.
(17) Pierloot, K.; Dumez, B.; Widmark, P.-O.; Roos, B. O. Theor. Chim Acta. 1995, 90, 87.

(18) Andersson, K.; Blomberg, M. R. A.; Fülscher, M. P.; Kellö, V.; Lindh, R.; Malmqvist, P.-A.; Noga, J.; Olson, J.; Roos, B. O.; Sadlej, A.; Siegbahn, P. E. M.; Urban, M.; Widmark, P.-O. MOLCAS, Versions 4 and 5; University of Lund: 1998, 2002.

(19) Roos, B. O.; Andersson, K.; Fülscher, M. P.; Serrano-Andrés, L.; Pierloot, K.; Merchan, M.; Molina, V. THEOCHEM 1996, 388, 257.

(20) Parker, C.A. Photoluminescence of solutions; Elsevier: Amsterdam, 1969, 161.

(21) Cook, R. L.; Kirchhoff, W. H. J. Chem. Phys. 1967, 47, 4521.

(22) Kirchhoff, W. H.; Wilson, E. B. J. Am. Chem. Soc. 1962, 84, 334.

(23) (a) Zibarev, A. V.; Lork, E.; Mews, R. J. Chem. Soc., Chem. Commun. 1998, 991. (b) Borrmann, T.; Lork, E.; Mews, R.; Stohrer, W. D.; Watson, P. G.; Zibarev, A. V. Chem. Eur. J. 2001, 7, 3504.

(24) Borrmann, T.; Zibarev, A. V.; Lork, E.; Knitter, G.; Chen, S.-J.; Watson, P. G.; Cutin, E.; Shakirov, M. M.; Stohrer, W.-D.; Mews, R. Inorg. Chem. 2000, 39, 3999.

(25) Allen, F. H.; Kennard, O.; Watson, D. G.; Brammer, L.; Orpen, A. G.; Taylor, R. J. Chem. Soc. Perkin Trans. 1987, 2, S1.

(26) Kitaigorodski, A. I.; Zorki, P.M.; Belski, V. K. Structure of organic compounds; Nauka: Moscow, 1970.

(27) (a) Leitch, A. A.; McKenzie, C. E.; Oakley, R. T.; Reed, R. W.; Richardson, J. F.; Sawyer, L. D. Chem. Commun. 2006, 1088. (b) Beer, L.; Brusso, J. L.; Haddon, R. C.; Itkis, M. E.; Kleinke, H.; Leitch, A. A.; Oakley, R. T.; Reed, R. W.; Richardson, J. F.; Secco, R. A.; Yu, X. J. Am. Chem Soc. 2005, 127, 18159. 